\title{
Soil Structure Interaction Effects on R C Structures Subjected to Dynamic Loads
}

\author{
I. Krishna Chaitanya, Balaji K.V.G.D, M. Pavan Kumar, B. Sudeepthi
}

\begin{abstract}
From the past studies, every engineering structure was designed to withstand all external and internal forces applicable to the structure. For this many design methods are implemented and different techniques are found manually, experimentally and practically. One of the parameters which influence the analysis results is, support condition of the structure. Assuming fixed or pinned support in regular analysis of structure considering soil interaction with foundation may not produce accurate results as support condition differ by type of soil ie., loose, medium or hard \& their characteristics. So, there is need to study about structural interaction with soil and their outcome deeply. Now a day's soil structure interaction studies are playing major role in the analysis \& design of structures. Many studies are carried out on structure interaction of soil considering seismic or lateral forces. This paper reviews the studies carried out on structural interaction with soil and its impacts on various reinforced concrete buildings subjected to dynamic loads.

Keywords: Structural interaction of soil, Seismic loads, foundations, Time history analyses, Impact loads
\end{abstract}

\section{INTRODUCTION}

Predictable structural design procedures have less scope on SSI effects. In comparatively stiff soil such as low-rise constructions and straight, rigid backfill walls effects and neglecting interaction with soil is inexpensive for light weight structures. The outcome of the structural soil interaction effect but, it becomes distinguished for significant building resting on comparatively loose clay soils.

If system was backed on smooth soil deposit, foundation's failure to adhere to the free field movement deformations would trigger the structure's base movement to diverge from the unrestricted field movement. Also, the structure's active response itself would cause to deform supportive soil. This technique, where the soil's reaction affects the structure's movement and the structure's reaction affects the soil's movement, is called SSI. It is also important for the tightly spaced building that, when the comparative displacement is big, may be susceptible to pounding.

* Correspondence Author

I. Krishna Chaitanya, Assistant Professor, Raghu Engineering, College, Visakhapatnam, India.

Prof. K. V. G. D. Balaji, Registrar GITAM (Deemed to be University), Visakhapatnam,India.

Mr. M. Pavan Kumar, Associate Professor, Department of Civil Engineering, Sanketika Vidya Parishad Engineering College, Visakhapatnam, India.

B. Sudeepthi, Assistant professor, Department of Civil Engineering, Raghu Engineering College Visakhapatnam, India.

(C) The Authors. Published by Blue Eyes Intelligence Engineering and Sciences Publication (BEIESP). This is an open access article under the CC BY-NC-ND license (http://creativecommons.org/licenses/by-nc-nd/4.0/)
Revised Manuscript Received on December 30, 2019.

To hold the SSI drawback properly, it is required to have some evidence of the quake wave propagation through the soil medium for two main reasons. Firstly, once the unstable waves circulate through the soil as Associate in ground motion, their active features depend on the adjustment of the bedrock signal.

Furthermore, data on the soil medium's shaking characteristi cs is incredibly useful in determining soil resistivity function s and setting limitations for a semi-infinite soil medium when analyzing wave circulation using arithmetical methods. To know the influence of native soil situations in changing the character of free field ground motion it's terribly essential to hold the nomenclature of native website result.

The first vital structure wherever the dynamic result of soil was thought of within the analysis in trade in Republic of India was the 500Mega Watt rotary engine foundation for Singrauli.

The scales of socio-economic indemnities produced by associate shaking rely near an excellent level on the features of the robust ground motion. it's been standard that tremor ground signals result mostly from the 3 factors, namely, supply features, drive path of waves, and native web location situations. Also, the Soil-Structure Interaction draw back has become a chief feature of Structural Engineering with the looks of huge constructions on clay soils like nuclear power units, concrete and earth dams, Underground buildings, bridges, tunnels and structures might also need obvious attention to be to the issues of foundation soil interaction.

When light-weight elastic system is made on a really rigid hard base, it is said that the involved movement at the base of the framework is equal because of the free-field earthquake wave. Where the building is incredibly large and inflexible, and therefore the foundation is comparatively smooth, the motion at the bottom of the structure could also be considerably totally different than the free-field surface motion.

\section{LITERATURE REVIEW}

Massumi and Tabatabaiefar ${ }^{1}$ [2008] studied a measure for considering structural soil collaboration properties in seismic proposal of ductile-reinforced moment resisting concrete frames according to Iranian codes. various dimensional specifications of frames like 3,5,7 and 10 storey with different bays properties are modeled in SAP 2000 and geotechnical specifications of soil type II (loose), III (medium) and IV (hard) soils are considered. 
3D quadrilateral elements of $4 \mathrm{~m}$ wide have been used for finite element design of soil and modelled using finite element method analysis in software SAP 2000. All considered models are analyzed for earthquake ground motions of Abbar, El-Centro, Naghan and Rudbar. From the research it was found that, impacts of structural soil collaboration are crucial for seismic modelling for constructing greater than 7 floors based on groundwater form III(medium) and greater than 3 floors based on ground form IV(hard). Kabir Shakya and Anil Wijeyewickrema ${ }^{2}$ [2009] Conducted a mid-column survey of multi-story strengthened concrete structures taking into account soil impacts. Consideration is given to structural designs of 5,9 and10-story houses. Impact components composed of a gap component called kelvin-voigt are viewed to incorporate the effect of base-soil communication and pounding among structures. The constructions considered are experienced with extreme impact pressures and inter-story movements due to nearby earthquakes for both static base and elastic base cases. From the results it has been concluded that decrease in impact forces are detected when the underlying base soil effect is measured and the extreme inter-story movements occurred when there is no pounding. Muberra Eser and Cem Aydemir ${ }^{3}$ [2012] By considering soil interaction with structure conduct of elastoplastic for 64 separate earthquake movements information collected on distinct location circumstances such as rock, steep soil, smooth soil \& very smooth ground, the resistance decrease factor for a single grade of liberty scheme was explored. The interacting structural with soils are designed and evaluated with efficient time, efficient damping and efficient ductility standards that differ after the static base case. Newmark method for implementation at an in-house computer program has been adjusted for this inflexible period history analysis. The final Outcomes are compared with fixed-base cases calculated. A new comparison is planned for the interacting system strength reduction factor as a purpose of the system structural period $(\mathrm{t})$, the ductility ratio $(\mathrm{u})$ besides the expansion period ratio $(t / t)$. It is found that the relationship of the soil structure decreases the strength reduction variables for soft soils, thus resulting in non-conservative planning forces using fixed-base strength reduction variables for interacting structures. Sayed Mahmoud and Saud Gutub ${ }^{4}$,[2013] Studies on earthquake resulted in pounding-involved soil flexibility reaction of base-isolated structures. To capture the pounding power, a nonlinear effect model is integrated. Moreover, an effective separate-component model is implemented to depict the soil's turning and plane motions. The vibrant reaction of the isolated construction lying on various versatile foundation materials and strikes the neighboring abutment and the respective reaction of the construction sitting on stiff foundation land. Two ground movement documents are used as excitations from two distinct areas. The findings indicate a important effect on active response of isolated structures during earthquakes by concurrent impact by pounding of base-isolated and base flexible foundation. Inclusion of structural soil interaction properties has been discovered to boost the amount of effects with the adjacent obstacle and decrease the caused impact strength values. The reaction of base-isolated structures differs with superstructure time intervals, base elasticity and breach dimensions among base and neighboring support.

Tufan Cakir ${ }^{5}$ [2014] Studied on the impacts of backfill and subsoil contact on cantilever wall seismic performance. To study the seismic comeback of the cantilever wall, a 3-dimensional finite element design with a viscous edge is developed. Analytical examinations have been performed using the method of modal analysis. Some comparisons on lateral movements and tension reactions are produced by altering the soil properties. From the outcomes, it is found that backfill and subsoil interactions significantly affect the lateral displacements and pressures in the wall, and the cantilever retaining wall's vibrant conduct is extremely susceptible to the soil material's mechanical characteristics. Behzad fatahi ${ }^{6}$ et al., [2014] has done the Comparison of the structural soil interaction with the location effect for seismic design of high-rise buildings on smooth loam by creating 3 structural designs, including 5 story, 10 story and 15-story structures, simulated with two types of soil. A shear wave velocity of fewer than $600 \mathrm{~m} / \mathrm{s}$, depicting loam categories $\mathrm{d}_{\mathrm{e}}$ and $\mathrm{e}_{\mathrm{e}}$ as classified as 1170.4-2007 (Australian earthquake action) having 30 meter bedrock depth. After conducting inflexible active analysis under the effect of 4 distinct earthquake floor movements, structural parts of particular frames were intended according to as 3600:2009 (Australian standard for concrete constructions). The above models were then analyzed under three distinct border circumstances: (i) Static basement under straight impact of tremor data (ii) Rigid basement considering local location impact altering only earthquake record and (iii) Flexible-base (considering complete soil-structure interaction). From the outcomes it was determined that conventional inelastic design method by including only local site effect without soil-structure interaction, cannot properly ensure environmental safety for mid-rise structures resistant to smooth soil deposits above 5 floors. Karabork ${ }^{7}$ et al., [2014] Effect of structural interaction with soil on base-isolated structures reaction was explored. This research evaluated the vibrant conduct of multi-story constructions that were constructed on smooth soil with elevated damping rubber bearing structural foundation. Different models have been created with and without account of connection between soil and structure. All the structure and the soil were linearly shown, but they were non-linearly modeled with high damping rubber bearing. The conduct of the given designs was evaluated with sap2000 computer software under dynamic conditions. The earthquakes of Erzincan, Marmara and Duzce were selected as surface movements. In inaccessible and fixed-base constructions with soil-structure interaction and without soil-structure interaction, the displacements, forces at shear base, top-story speeding up, foundation level accelerations, phases and peak inner pressures are contrasted. The findings show that communication between soil and structure is an significant consideration (in terms of earthquakes) to be considered when selecting a suitable isolator for smooth soil base-isolated constructions. Jayalekshmi and Chinmayi ${ }^{8}$ [2015] Conducted a survey on the seismic conduct of Rein-f forced framed wall structures in accordance with IS 1893-2002(part-I) and IBC regulations by considering the seismic conduct of multi-story strengthened, concrete small and large structures of various heights including and excluding reinforced wall backed on raft foundations integrating soil flexibility effects.

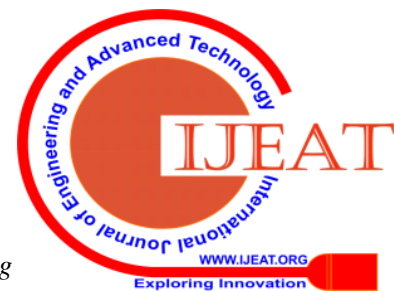


Analysis was performed using finite element technology ls dyna by three-dimensional models of 6 distinct shear wall locations based on 4 distinct soils. The research examines distinctions in the spectral speed ratio (sa / g), base shear and store shear acquired in accordance with the seismic regulations of the Indian normal code: 1893-2002 and Global Building Code IBC 2012. Finally, these findings of the research show that the basic shear scores acquired in accordance with the IBC regulations are greater than the values.

Sherya Thusoo ${ }^{9}$ et al.,[2015] studied behavior of building with interaction of soil by changing soil types for a multi-storey building considering different soils (loose, medium and very stiff clays ) and supports were designed as static and elastic base condition. they used El-Centro Earthquake acceleration data to know the behavior of all the considered models. fem based software package ANSYS is used for the study. Bedrock and reinforced concrete were modeled with solid 45 and solid 65 elements respectively. Based on the obtained results they compared lateral displacement and acceleration with respect to time for all the models with different soil conditions. they also compared the natural time period of all the models. They concluded that lateral displacement is less in hard and medium soil when compared with soft soils, when stiffness of base decreases, there is a drastically change in spectral acceleration response pattern. Time period on all the comebacks rises when soil contact is considered.

Jayalekshmi and Chinmayi ${ }^{10}$ [2015] The soil interaction with structure of RC framed structures with different forms of reinforced concrete walls was researched in accordance with IS 1893-2002(part-I).By means of finite element modelling software LS DYNA, soil foundation were modelled by way of raft foundation considering building with various aspect ratio (ie.,1, 1.5, 2,3\& 4) and four different shapes (Bare frame, rectangular, cylindrical, corrugated) with various shear wall thickness for , rectangular, cylindrical, corrugated walls. Soil profile type rock, dense soil, stiff soil and soft soil are considered and adjacent forces, shear base designs are calculated with essential natural period, identical design response spectrum code of practice and concluded that corrugated shear wall building shows less shear at base in reinforced concrete wall building with aspect ratio up to 2, with increase in comparative toughness for raft $\left(\mathrm{k}_{\mathrm{rs}}\right)$ natural period increases and decreases with decrease in relative stiffness for super sturcture $\left(\mathrm{k}_{\mathrm{sb}}\right)$.

Bhojegoeda and Subramanya ${ }^{11}$ [2015] carried out study of structural soil interface of enclosed structure supported on various kinds of foundations. Regular and irregular buildings are analyzed for static and elastic support for 5,10\&15 storey buildings considering different soil limits like type of soil, $\mathrm{N}$ value, mass density, shear wave velocity\& passion ratio. Using software E-tabs package different buildings are modeled and considered for buildings with soil, medium, hard type. From this study the author has concluded that, when altitude of building increases equivalently shears at base, period and response similarly increase and pile basement resting on solid, mid and loose can be treated as static, since there is no much difference in the structure behavior.

Roopa $^{12}$ et al.,[2015] Worked on the soil structure interaction assessment of a raft-based construction under clayey soil situation for a raft-based construction $g+12$. Data on in-situ soil circumstances shall be done by borehole testing, and the information acquired shall be used for evaluation. Construction was regarded for the research with a set base and a raft foundation. The vertical, horizontal, swinging and bending characteristics of soil springs are regarded by Richart and Lysmer. Seismic reaction tests are conducted with regard to the building's storey drift, foundation shear and normal time span with difficult, medium and soft soils for a set and versatile foundation with and without contact with soil. Etabs and Sap2000 software package were used for building modeling and soil modeling. From the results it was determined that storey drift is maximum in the middle storeys in case both static and elastic condition, the base shear is twice in elastic base when compared to static base and there is a substantial growth in response of high constructions Once soil interaction is considered as elasticity induced to base by smoothness of clayey soil.

Quoc van Nguyen ${ }^{13}$ et al., [2016] investigated on effects of shallow foundations on seismic response of mid-rise moment resisting building. Study on 15 storey frame resisting resting on shallow basement of various sizes were calculated statistically using ABAQUS software. Several boundary conditions were assigned to numerical model to simulate free field boundaries and appropriate contact elements capable of modelling, sliding and separation between the foundation and soil elements are also considered. The study on influence of basement size on the natural frequency of the system and structural response spectrum was carried out. Comparison between cases of soil-foundation-structure systems for different sized foundations and static base conditions (excluding soil-foundation-structure interaction) in terms of lateral deformations, inter-storey drifts, rocking, and shear force distribution of the structure was done in the study. From the outcomes it was concluded that, the size of a shallow basements influences the active characteristics and seismic response of the building due to interaction between the soil foundation and structure. So, design engineer should carefully consider these parameters in order to ensure a safe and cost-effective seismic design.

Nitish kumar and Praveen ${ }^{14}$ [2016] Has done study on structural soil interaction effect on Multi-storey reinforced concrete framed constructions resting on raft basement under Earthquake caused agitation. By using SAP-2000 structural design software the building is modeled for 10,15,20 and 25 storey building over a raft basement resting on soft, medium and hard soil with varying raft thickness. Changes of foundation for both horizontal and vertical axes with rotational springs about mutually perpendicular axes are considered to estimate the soil elasticity. using the data of past Bhuj Earthquake, the analysis is carried out. They concluded that the variation in time period is due to soil flexibility and lateral displacement increases as the number of storey increases, as soil flexibility varies there will be increase in displacement, time period and bending moment with the influence of the parameter like soil types, varying raft thickness, soil medium and change in height of the building. bending moment increases with soil flexibility.Mehar ${ }^{15}$ et al.,[2016] Seismic reaction variety of mid-rise rein forced structures was researched owing to the impacts of soil structure interaction. 
Rc moment resistant of three types of 2-dimensional frame for 5,10\& 15 are considered. Various soil parameters are analyzed for considered rc frames and three Earthquake data of Loma Prieta, Kobe of Japan, Northridge California input motions are taken. Using Plaxis 2d v8.2 software package soil system is modelled for three types of soil class hard, medium and loose. Results obtained for seismic response for different storey heights, equivalent static spring stiffness for different soils, fundamental frequencies for different boundary conditions, seismic response for Loma, Kobe, Northridge. results are compared for maximum displacement to storey level for different input motions for firm, medium, loose and fixed base are carried out. they concluded that nonlinearity of medium and loose soil conditions vastly reduced in response at the top of structure when compared with the fixed base.

Chaithra ${ }^{16}$ et al., [2017] carried out a study on the analysis of interaction of soil with structure for water tanks filled with fluid. tanks with fluids with three type of soil flexibility conditions with varying modulus of elasticity of soil are considered. two different earthquake data far field and near ground accelerations as El- Centro and imperial valley earthquake respectively are taken. The displacement, base shear and the pressure in the fluid is calculated by taking the peak values of shear at the base, displacement and pressure for the tank with and without soil structure interaction are compared to know the interaction effect. From the analysis it was noticed that the peak pressure increased twice when compared to far filed to near field Earthquake. The pressure is maximum in soil type II(medium) with compared to type I(hard) \& III(loose) with both the earthquakes, the type of soil also effects the response of the tank when soil structure effect is considered.

Farhad Behnamfar ${ }^{17}$ et al., [2017] seismic behavior of building was studied by considering uplift and soil interaction with structure for two soil types D \& E of bearing capacity $200 \& 150 \mathrm{Kn} / \mathrm{m}^{2}$ respectively on nonlinear seismic response of structures. Several reinforced concrete and steel structures under different ground motions are considered. The foundation of the structures is designed with nonlinear compression of vertical no-tension springs. The overall soil-structure interaction scheme is designed within the Opensees software, and a nonlinear dynamic analysis is used to evaluate seismic conduct. Buildings ' nonlinear reactions are determined and contrasted in three instances: set base, elastic base without elevation, and elastic base with elevation. For the study Totally, 40 structure-soil cases each one under 10 consistent earthquakes specific to the building under study were investigated. From the results it is showed that almost in all of the cases considered, even for short moment frame systems, detachment of foundation from the bearing soil, or uplift, occurred under the earthquakes scaled to a design spectrum corresponding to severe seismicity. The maximum vertical drift, i.e. relative vertical displacement of two ends of a beam divided by the beam length, occurred for the case of a 12-story steel moment frame and was 0.009 or $0.9 \%$. No-tension soil springs at the foundation level results generally in larger story drifts. The maximum difference was observed to be $76 \%$ and $60 \%$ relative to the FB and SSI (with a tensile soil) cases that belonged to five-story steel braced frame buildings on the soil type E.

Lakshmi Pujitha and Hanumanth Rao ${ }^{18}$ [2017Studies conducted out on soil structure interaction surveys on a plane construction frame backed by a stack cluster integrated in cohesive soil by designing a four-story frame of three bays and pillars covered by a pile unit of clayey soil depicted by springs. Using Matlock equations p-y curves are derived and data obtained are used for modeling in ANSYS. the soil properties are obtained from triaxial consolidated undrained compression test. finite element modeling and analysis software Ansys is used for calculating the shear force and bending moment and non-linear analysis to calculate the lateral and vertical displacements, shear and bending in the frames with and without soil structure interaction. using combined 39 element in ANSYS for the cohesive soil is modeled with non-linear load transfer curves. From the outcomes it is found that forces in shear and the bending moment values of the standard column technique are more than those of the non-linear finite element analysis and also the soil interaction assessment.

Dimitrios Sotiriadis ${ }^{19}$ et al.,[2017] A research on the impact of nonlinear structural interactions with soil on seismic deformation for 3D structures on frictional \& cohesive materials was conducted. For this purpose, nine structures with distinct heights are regarded with distinct structural systems based on two kinds of land: cohesive and frictional ground carrying soil flexible using two distinct soil shear wave velocity measurements. 3D structures on cohesive and frictional surfaces focus on the possibility of quantitative differentiation with regard to set base conditions. All structures are subject to 65 bi-directional earthquake reports for which time history assessment is also carried out and found that the function of soil-foundation structure communication in not simply useful and significant parameters is earthquake ground movement information and structural system construction, soil flexible and earthquake frequency.

Yajun huang ${ }^{20}$ et al., [2018] In this research, for the dynamic analysis of soil-pile group-tall construction structures stimulated by wind stresses using the substructure technique, a streamlined three-dimensional calculation model is created. From synchronous stress readings carried out in a wind tunnel, wind loads acting on a 300-m construction in distinct wind directions and soil situations are acquired. The structural interaction with soil impacts on the first natural frequency, wind-made static displacement, displacement root mean square (rms) and speed rms are evaluated at the edge of high structures. Results found that the first natural frequency reduces with reducing ground shear velocity and the acceleration rms boost, while damping of the soil surface reduces the rms of displacement and the rms of acceleration rise. the first natural frequency reduces.

\section{Methodology}

From the literature, research was done on soil structure interaction for various soil types \& properties when interacted with different base foundations and structures. In these studies, many methodologies were used to show,

how the structure performs under seismic moment, various foundations types, cantilever wall, shear wall, elevated water tanks, various frames and buildings when soil structure interaction was considered. 


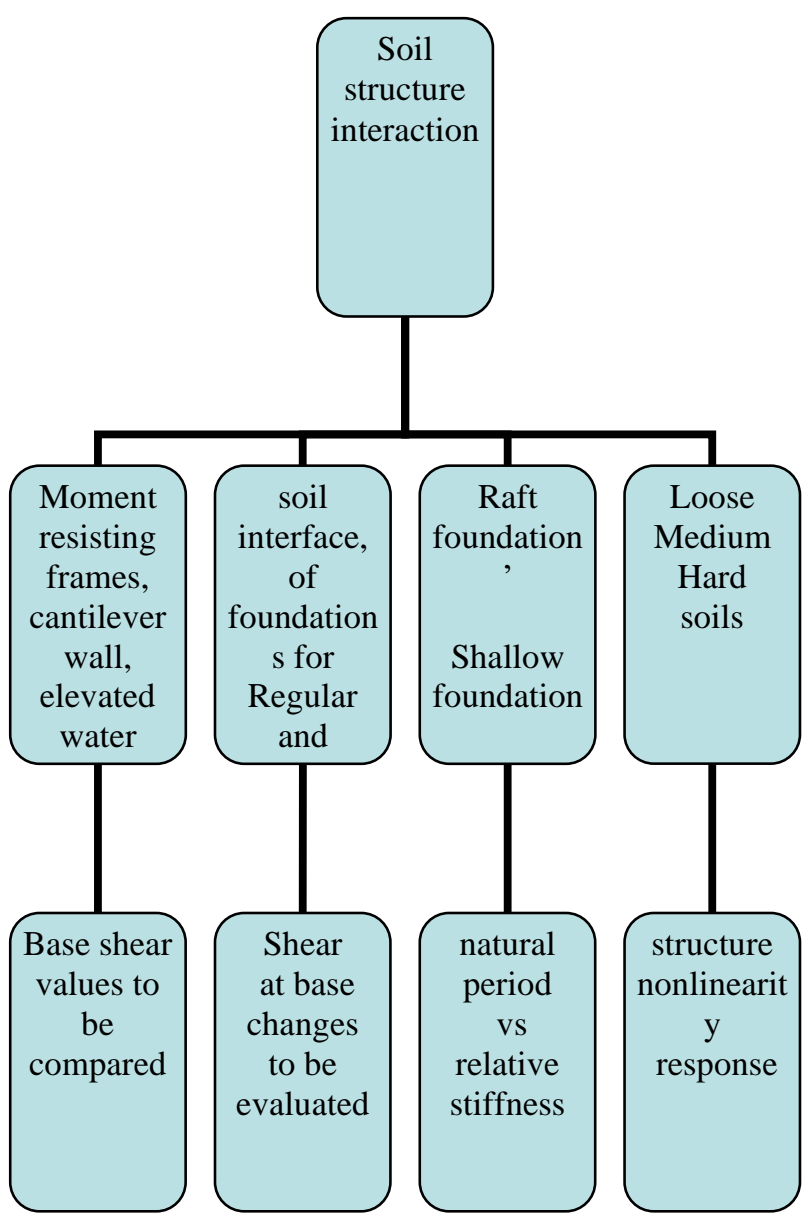

\section{RESULT AND DISCUSSION}

Table-1 shows the key inference of various authors from chronological literature survey on soil structure interaction subjected to dynamic loads.

Table-1Key inference from chronological literature survey

\begin{tabular}{|c|c|c|c|}
\hline Sno & $\begin{array}{l}\text { Time } \\
\text { line }\end{array}$ & Reference & Considerations \& outcome \\
\hline 1 & 2008 & $\begin{array}{l}\text { Massumi and } \\
\text { Tabatabaiefar }\end{array}$ & $\begin{array}{l}\text { soil collaboration properties, } \\
\text { seismic proposal, Iranian } \\
\text { codes. } \\
\text { High impact on greater } \\
\text { structures more than } 7 \text { floors. }\end{array}$ \\
\hline 2 & 2009 & $\begin{array}{l}\text { Kabir Shakya and } \\
\text { Anil C. } \\
\text { Wijeyewickrema }\end{array}$ & $\begin{array}{l}\text { soil impacts, base-soil } \\
\text { communication and pounding } \\
\text { among structures has less } \\
\text { impact forces with underlaying } \\
\text { base effect consideration. }\end{array}$ \\
\hline 3 & 2011 & $\begin{array}{c}\text { Muberra Eser } \\
\text { and Cem Aydemir }\end{array}$ & $\begin{array}{l}\text { soil interaction, cantilever wall } \\
\text { seismic performance, } \\
\text { new comparison for interacting } \\
\text { system strength. }\end{array}$ \\
\hline 4 & 2013 & $\begin{array}{l}\text { Sayed } \\
\text { Mahmoud1and } \\
\text { Saud Gutub }\end{array}$ & $\begin{array}{l}\text { Earthquake, pounding, soil } \\
\text { flexibility, rock, steep soil, } \\
\text { smooth soil \& very smooth } \\
\text { ground } \\
\text { Inclusion of soil interaction } \\
\text { properties are discovered. }\end{array}$ \\
\hline 5 & 2014 & Tufan Cakir & $\begin{array}{l}\text { impacts of backfill and subsoil, } \\
\text { lateral movements and tension } \\
\text { reactions, altering the soil } \\
\text { properties. } \\
\text { Backfill and subsoil interaction } \\
\text { affects lateral displacement. }\end{array}$ \\
\hline
\end{tabular}




\begin{tabular}{|c|c|c|c|}
\hline 17 & 2017 & $\begin{array}{l}\text { Farhad } \\
\text { behnamfar, seyyed } \\
\text { mohammad } \\
\text { mirhosseini } \\
\text { and hossein } \\
\text { alibabaei }\end{array}$ & $\begin{array}{l}\text { Seismic behavior, uplift and } \\
\text { soil interaction, borehole } \\
\text { testing, earthquakes specific. } \\
76 \% \text { for fixed base and } 60 \% \\
\text { soil mass base was seen when } \\
\text { storey drift was considered } \\
\text { with no-tension soil springs. }\end{array}$ \\
\hline 18 & 2017 & $\begin{array}{l}\text { Lakshmi Pujitha } \\
\text { and Hanumantha } \\
\text { Rao }\end{array}$ & $\begin{array}{l}\text { Soil structure interaction, } \\
\text { Matlock equations p-y } \\
\text { ANSYS. } \\
\text { Shear and bending are more } \\
\text { when standard column } \\
\text { technique is considered. } \\
\end{array}$ \\
\hline 19 & 2017 & $\begin{array}{l}\text { Dimitrios } \\
\text { Sotiriadis, } \\
\text { Konstantinos } \\
\text { kostinakis and } \\
\text { Konstantinos } \\
\text { Morfidis }\end{array}$ & $\begin{array}{l}\text { Soil on seismic deformation, } \\
\text { frictional \& cohesive } \\
\text { materials. } \\
\text { Soil structure interaction is not } \\
\text { simply useful and important } \\
\text { parameter in seismic } \\
\text { information, structural system } \\
\text { construction, soil flexible, and } \\
\text { earthquake frequency. }\end{array}$ \\
\hline 20 & 2018 & $\begin{array}{l}\text { Yajun Huang and } \\
\text { Ming Gu }\end{array}$ & $\begin{array}{l}\text { Soil-pile, wind stresses, } \\
\text { substructure technique } \\
\text { Natural frequency reduces with } \\
\text { reducing ground shear } \\
\text { velocity. }\end{array}$ \\
\hline
\end{tabular}

From the above discussions some of the outcomes are observed based on the soil structure interaction studied and seismic performance studies with various soil properties.

1. To accurately forecast the response of building, need to consider the effect of soil interaction with the structure.

2. To accurately estimate soil structure interaction, foundations effect has to be considered, as forces in structure components, basement and soil mass are significantly changed due to interaction with soil.

3. Wide range of studies are carried on soil structure interaction with foundation with loose, medium \& hard soils on RCC structures with shear walls also.

4. Settlements are found more in the loose and there is a change in total differential settlements as load redistribution significantly modifies, when soil properties are changed from loose to hard.

5. Soil Interaction behavior considering basement like raft foundation, grid foundation and pile foundation etc,. were less analyzed.

6. Studies on soil mass consideration as elasto-plastic, visco-elastic and visco-plastic interaction analyses are very limited.

\section{CONCLUSIONS}

The assessment of the present studies which are applied on structures interacting with soil analysis leads to the following results.

1. For studying soil-structure interaction effect finite element method is very important according to these studies.

2. Incremental iterative technique is found to be the most suitable and general one to perform nonlinear soil-structure interaction analysis.

3. It has been observed that, increase in seismic base shear of low-rise building frames resting on isolated footings when Soil-structure interaction is considered.

4. Soil structure interaction effect was evaluated only for seismic loads on various structures with geometric irregularities, stiffness irregularities and shear walls for different soil conditions. From the literature it was clear

that, soil structure interaction effects on buildings due to blast loads were not studied.

5. But there is less focus on soil structure interaction effects due to blast impact loads on the structure.

6. Soil structure interaction along with blast loads, sudden impact loads are to be considered as these areas of study is neglected and further these studies bring out new research study and impact in better design of structures.

\section{REFERENCES}

1. Massumi and Tabatabaiefar " A criterion for considering structural soil interaction effects in seismic design of ductile RC-MRF according to Iranian codes" $14^{\text {th }}$ world conference on earthquake engineering, Beijing, china, October 12-17,(2008).

2. Kabir Shakya and Anil C. Wijeyewickrema "Mid-Column Pounding of Multi-Story Reinforced Concrete Buildings Considering Soil Effects", Advances in Structural Engineering Vol. 12 No. 1, (2009).

3. Muberra Eser and Cem Aydemir "The effect of soil-structure interaction on inelastic displacement ratio of structures" Structural Engineering and Mechanics Volume 39, Number 5, September10, pages 683-701 DOI: http://dx.doi.org/10.12989/sem.2011.39.5.683, (2011).

4. Sayed Mahmoudland Saud Gutub “ Earthquake Induced Pounding-Involved Response of Base-Isolated Buildings Incorporating Soil Flexibility" Advances in Structural Engineering Vol. 16 No. 12, (2013).

5. Tufan Cakir "Backfill and sub-soil interaction effects on seismic behavior of a cantilever wall" Geomechanics and Engineering Volume 6, Number 2, pages 117-138, (2014)

6. Behzad Fatahi, S. Hamid Reza, Tabatabaiefar and Bijan Samali "Soil-structure interaction vs Site effect for seismic design of tall buildings on soft soil" Geomechanics and Engineering Volume 6, Number 3,, pages 293-320 , (2014).

7. Karabork, Deneme and Bilgehan "A comparison of the effect of SSI on base isolation systems and fixed-base structures for soft soil" Geomechanics and Engineering Volume 7, Number 1,, pages 87-103 , (2014).

8. Jayalekshmi and Chinmayi " Seismic behavior of RC framed shear wall buildings as per IS 1893 and IBC provisions" Geomechanics and Engineering Volume 9, Number 1, , pages 39-55,(2015).

9. Sherya Thusoo, Karan modi, Rajesh kumar and Hitesh madahar "Response of building with soil structure interaction with varying soil types", International journal of civil environmental engineering, vol-9, no-4, (2015).

10. B R Jayalakshmi and H.K. Chinmayi "Soil structure interaction effect on seismic force evaluation of RC framed buildings with various shapes of shear wall: as per IS 1893 and IBC" Indian geotech J (July-september) 45(3):254-266,DOI 10.1007/s40098-014-0134-2 , (2015).

11. Bhojegowda and Subramanya "Soil structure interaction of framed structures supported on differect types of foundations", international research journal of engineering and technology, vol-2, Issue-05, E-ISSN: 2395-0056, P-ISSN:2395-0072, (2015).

12. Roopa, Naikar and Prakash" Soil structure interaction analysis on a RC building with raft foundation under clayey soil condition" International journal of engineering research \& technology, vol.4, issue 12, ISSN :2278-0181, (2015).

13. Quoc Van Nguyen, Behzad Fatahi and Aslan S. Hokmabadi " The effects of foundation size on the seismic performance of buildings considering the soil-foundation-structure interaction" Structural Engineering and Mechanics Volume 58, Number 6, pages 1045-1075 , (2016).

14. Nitish kumar and Praveen "study of soil structure interaction effect on multi-storey RC frame structures resting over raft foundation under earth caused agitation" International Journal of Civil and Structural Engineering research, vol.4, pp: (95-102),ISSN 2348-7607, (2016).

15. Maher, Osama and Mohamed "variation of seismic response of mid-rise RC buildings due to soil structure interaction effects" International Journal of Civil Engineering and Technology, Volume 7, Issue 1, pp. 220-240, Article ID: IJCIET_07_01_019, (2016). 
16. Chaithra, Krishnamoorthy and Naurin Nafisa " Analysis of soil structure interaction on response of tanks filled with fluid" International Journal of Civil Engineering and Technology, Volume 8, Issue 7, pp. 813-819, Article ID: IJCIET_08_07_088, ISSN Print: 0976-6308, ISSN Online: 0976-6316, (2017).

17. Farhad behnamfar, seyyed mohammad mirhosseini and hossein alibabaei "seismic behavior of structures considering uplift and soil-structure interaction" volume: 20 issue: 11, page(s): 1712-1726, (2017).

18. Lakshmi Pujitha and Hanumantha Rao "Soil structure interaction study on plane building frame supported on pile group embedded in cohesive soil" International Journal of Civil Engineering and Technology, Volume 8, Issue 1, ISSN Print: 0976-6308 and ISSN Online: 0976-6316, (2017).

19. Dimitrios Sotiriadis, Konstantinos kostinakis and Konstantinos Morfidis "Effect of nonlinear soil-structure interaction on seismic damage of $3 \mathrm{D}$ buildings on cohesive and frictional soils" , Bull Earthquake Eng , 15:3581-3610, DOI 10.1007/s10518-017-0108-8, (2017).

20. Yajun Huang and Ming Gu "Wind-induced responses of supertall buildings considering soil-structure interaction" Wind and Structures Volume 27, pages 223-234, (2018).

\section{AUTHORS PROFILE}

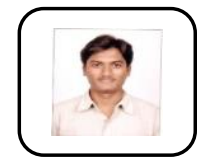

I. Krishna Chaitanya: Research scholar GITAM (Deemed to be University), working as Assistant Professor in Raghu Engineering College, Visakhapatnam, INDIA.

Email: ikchaitanya.123@gmail.com

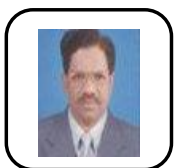

Prof. K. V. G. D. Balaji, M.Tech (Structures), Ph.D.is civil engineer with 35 years teaching experience. GITAM (Deemed to be University). He is a member in various prestigious societies and professional bodies like ISTE, ISCMS, ISRMTT, IRC, INSDAG, ISRS, ISET, IGS, CMSI, FIE, FIV, FIPHE. Presently Registrar GITAM (Deemed to be University), Visakhapatnam. He is a Licensed Structural Engineer of VUDA \& GVMC Member (CED 57) and member of Bureau of Indian Standards. His yeoman services as a lecturer, professor, and Head of Department enriched the knowledge to thousands of students. He is a stalwart of structural analysis and has nearly $9 \mathrm{PhDs}$ to his credit. More than 50 papers were published in various esteemed reputable National and International Journals. He published four books in various Areas. He received so many prestigious awards and rewards.)

Email: balajigitam@gmail.com

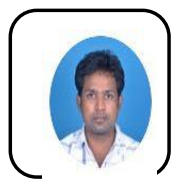

Mr. M. Pavan Kumar , Associate Professor, Department of Civil Engineering, Sanketika Vidya Parishad Engineering College, Visakhapatnam, INDIA.

Email: pavanidea@gmail.com

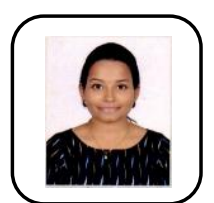

B. Sudeepthi, Assistant professor, Department of Civil Engineering, Raghu Engineering College Visakhapatnam, INDIA.

Email: sudeepthi1268@gmail.com 